\title{
A Gamified Approach to Improving Student's Participation in Farm Practice - A Case Study of Landmark University
}

\author{
https://doi.org/10.3991/ijim.v13i05.9404 \\ Adebayo Omotosho ${ }^{(\varpi)}$, Truman Tyoden, Peace Ayegba, Joyce Ayoola \\ Landmark University, Omu-Aran, Nigeria \\ omotosho. adebayo@lmu.edu.ng
}

\begin{abstract}
The importance of students' involvement in classroom and nonclassroom university courses cannot be overemphasized in the process of learning. But, students for several reasons must be motivated to enhance their continuous participation, especially in non-classroom courses. Landmark University is an agrarian-based institution and students are expected to actively take part in at least one agricultural course irrespective of their specializations. Students commitments to Farm Practice courses are core to graduation despite many students not meeting the expected level of dedication early. Gamification is the process of using game strategies and techniques to actively engage and motivate audiences and to solve problems. Using a database of agricultural resources from Landmark University Teaching and Research Farm, a prototype for a gamified mobile app for engaging students in Farm Practice is developed. Game features such as point, leaderboard, and scoresheet were embedded. The application performance was evaluated by a total of fifty students and $70 \%$ of the students claimed that their interests in Farm Practice were positively affected after using the app for the first time.
\end{abstract}

Keywords - Gamification, farm practice, participation, user-engagement, android, mobile app

\section{Introduction and Background}

Games generally can provide fun and engage players at the same time, it is part of our daily routine to derive fun from something. The idea does not necessarily mean creating a game, and with respect to education, it means simulating game experience to make education and learning process more fun and engaging, without undermining its credibility [1]. Studies have shown that using game-based mechanics, aesthetics and game thinking to engage people, can better motivate action, promote learning, and solve problems [2,3]. Gamification is the use of game elements in the non-gaming environment. Gamification works with the state of mind of a person, it can, therefore, impact on user development of interest on different skill based on system design [4]. As described in $[5,6,7]$, the distinctive elements that are key to gamification are: 
- Reward/ badges - this is the most elementary gamification element used and it is a mechanism used in awarding participant with response to accomplishment of task activities

- Challenges/tasks/quest - these are task a participant must fulfill within the game

- Performance graph - a visual representation of participant's performance history

- Points - points are accumulated as a result of performing task within the gamification environment

- Levels - these are the stages in gamification structure, which participants pass depending on points

- Users/Participants - these are the people involved in gamification e.g. employees for companies, students for educational purposes, patients for health care

- Progress bar - shows the current status of a player towards achieving set goal.

Gamification in education appeared to have no downside as game techniques and mechanisms can be implemented in the learning process as activities designed to achieve certain learning objectives $[6,8,9,10,11]$ Students learning with games at both high school and university level have performed better in their assessments than those learning without. Learners have been reported to complete tasks faster and they have also found the experience to be more engaging and pleasant than when using nongamified versions $[12,13,14,15]$. Games can carry educational content in an implicit manner, which means that serious game designers can teach without overtly teaching based on the system design. This category includes studies that propose gamified solutions to enhance the way students learn, maximizing the results of the learning process $[16,17,18]$. In addition, the majority of related works show that systems should be segmented into different levels. These levels should be designed such that users must actively engage in activities within the gaming environment to scale through stages $[19,20]$. From a psychological perspective, gamification is not determined by the elements of the system developed but by the experience of a user [16]. Gamification is effective in a university setting and regarding the actual techniques used, leaderboards were found to be highly motivating, with points and ranks following, and progress bars, the end prize, and badges found to be least motivating [21].

Ordinarily, gamification involves the general application of elements of game design in a non-gaming surrounding, they are basically used for promoting user's engagement, modify psychology and aid natural learning. Whereas serious games provide not just entertainment to users, they serve other purposes and provide motivation in the various aspect of human life like education, government, and engineering, among others [22] [23]. Serious game simulation often includes storytelling feature where users experience a kind of sequence of story narration as they progress in the game. Serious games have the capability of influencing our behaviours over time and usually embed a combination of the features of learning, fun, and competition.

There are different approaches to gamification. We have the lean approach which mimics and simulates an entire process or activities involved in a system. Lean gamification environment usually looks like the real world where the user will use the learned skills. For example, a paramedic could be trained in a fictitious world on how to resuscitate a patient. This approach is usually detailed because users navigate vari- 
ous components of the system in order to experiment with and understand the different behaviours and possible outcomes of the system. Lean gamification favours gamifying abstract learning process rather than the content itself [24] [25]. Shallow and deep gamification removes complexities by giving a serious game a more game-like representation, they involve framing, which places much importance on the context where act ivies take place. The difference between the two is that shallow gamification makes use of simpler or fewer game mechanics (components) than deep gamification. [26] showed that gamification could be more engaging even without gaming elements, in addition, it was also found that there is no significant difference in the level of motivation induced by deep gamification and shallow gamification. Hence, the author concluded that the framing of a task as a game need not be complex in order for users to enjoy or positively engage in the activities.

Landmark University (LMU) is an agriculture-based institution where Farm Practice (FP) is prerequisite for graduation. Attendance system currently used in Landmark University FP makes use of student's ID barcode scanning and sometimes written attendance which is then uploaded online. However, a total of $75 \%$ attendance must be met as criteria for writing an examination. There have been several cases of inconsistencies and lackadaisical attitudes in students' FP attendances despite being a compulsory course. Many students are not propelled to attend because:

- The course has zero credit unit

- They are enrolled for a non-agriculture course

- General lack of motivation to participate in FP

In this paper, in a bid to increase students' turnout and interest during FP in LMU, a structured gamification system is developed to increase students' engagement and motivation. Farm activities are presented in the form of reward-based challenges where participants are obliged to complete a task and are graded based on their performance.

\section{System Design}

Components of the prototyped system in Figure 1 is thus described:

- Users: These are the people involved in gamification e.g. employees for companies, students for educational purposes, patients for health care. In this context, targeted users are the students that are going to interact with the application regularly. Users are expected to login the system using their university accounts to access the features therein.

- Users' device: The device is the application access platform a user has to his or her system. The application is an Android-based system; therefore, an android device is the required specification to run the gamified system.

- Database: The database contains the files that are uploaded on the gamified system. Images and text captured from LU farms were used to populate the database. 
- Farm instructor: The farm instructor tutor's students on the farm. The instructor also supervises the question and crosscheck the corresponding uploaded images for a mismatch.

- Game: This is the gamified part of the system; it is the core part where users can play games available.

- Leaderboard: This is a visual representation of the participant's performance history. It contains the performance history of every user in the system community in a hierarchical order.

- Score sheet: Shows the current status of a player towards achieving the set goal

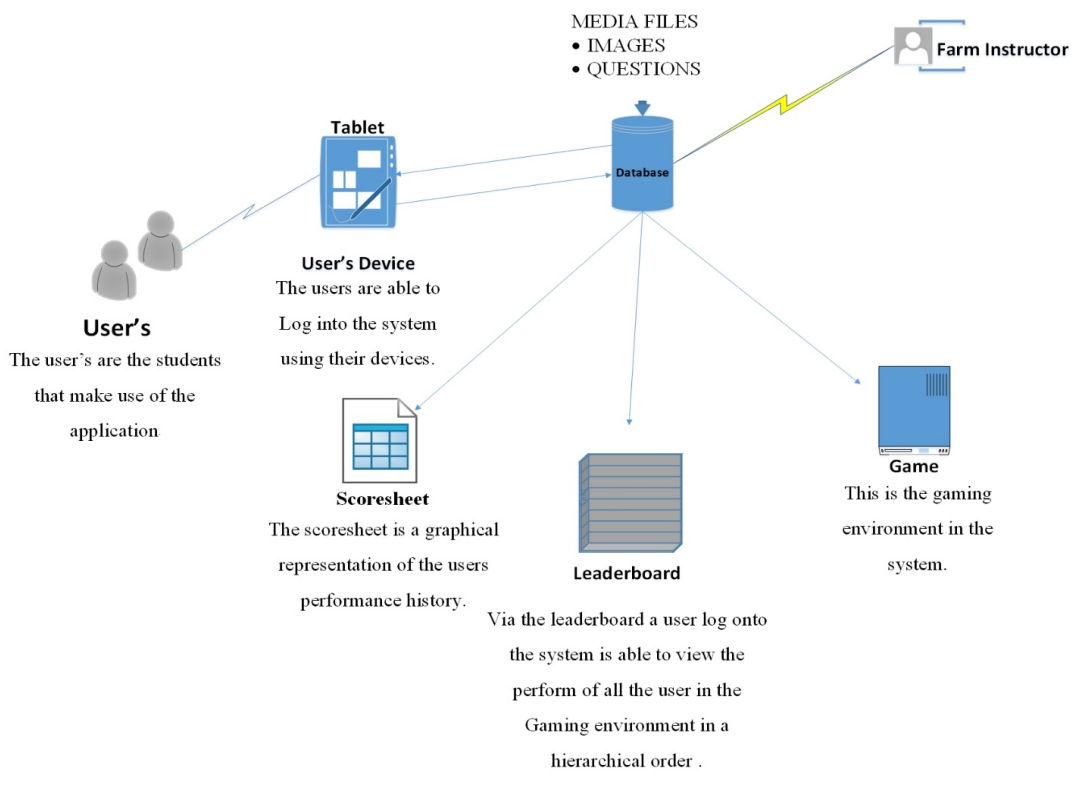

Fig. 1. Conceptual diagram

\subsection{Features of proposed system}

The gamified system is expected to launch with a startup page that prompts a user to login before access to the application is granted. The features below listed are the components that make up the system:

- Leaderboard page: It is a visual representation performance history of participant's based on heights attained in order of hierarchy. A leaderboard is one of the most widely used game elements and can often be used as an instrument for measuring the rate of skill acquisition and performance of users. As important as leaderboards are, they are not always the yardstick of success as not all users find them influential [27]. Examining the effect of a leaderboard is not the goal of this paper and it is only adopted because of its popularity. The leader board is a simple design that displays the players' id and scores. 
- Score sheet: Shows the current status of a player towards achieving a set goal. The learning goals are derived from a syllabus which is designed in conjunction with the farm administrator and farm practice leaders.

- Game: This is the main interface where the users play the game. It is in form of a grid box containing images collected for Landmark University Teaching and Research Farm. Participants were to answer questions based on the images and the hints loaded per the game interface.

- Setting: On the setting platform, the user is been able to mute the game sound and enlarge or decrease the text of the application

\subsection{Data gathering}

A total of 72 images were captured from the LMU Teaching and Research Farm, the breakdown of the data gathered is shown in Table 1

Table 1. Farm Items Documentation

\begin{tabular}{|l|c|l|}
\hline \multicolumn{1}{|c|}{ Department } & Images & \multicolumn{1}{c|}{ Items } \\
\hline Animal husbandry: Goathouse & 8 & $\begin{array}{l}\text { African Dwarf Goats (3) } \\
\text { Maradi or Red Sokoto (2) } \\
\text { Jamnapari (3) }\end{array}$ \\
\hline Animal husbandry: Breeder house & 8 & $\begin{array}{l}\text { Yankasa (6) } \\
\text { West Africa Dwarf (WAD) (2) }\end{array}$ \\
\hline Mechanical & 9 & Tractor and components Grainer \\
\hline Screen house & 8 & Deep water culture Hydroponics system \\
\hline Plant science & 8 & $\begin{array}{l}\text { Cucumber (3) } \\
\text { Melon (3) } \\
\text { Irrigation system (2) }\end{array}$ \\
\hline Brooder house/ poultry & 7 & $\begin{array}{l}\text { Broiler } \\
\text { Intensive housing }\end{array}$ \\
\hline Animal husbandry: Pig house & 8 & $\begin{array}{l}\text { Landrace breed (6) } \\
\text { Duroc breed (2) }\end{array}$ \\
\hline
\end{tabular}

\subsection{Development tools}

During the development process of the system, various tools were used for the implementation of different areas and functions of the system. They include:

- Android SDK: This is a development tool developed Google to design and build applications for systems running the Android platform. The development kit is shipped with some starter sample projects with their source code, an emulator, and important libraries necessary for developing applications for the Android platform. Android itself was developed using JAVA programming language and therefore supports a program written in JAVA. Dalvik which runs on Linux kernel was the preferred virtual machine for running and simulating actual the Android operating system. In addition, Android SDK inbuilt application programming interface (API) libraries and tools were used to test and debug the developed app 
- Sublime text: This is the cross-platform editor used for writing the application code and sublime itself is a proprietary editor with a Python API. By default, it supports several programming and mark-up languages. Sublime allows users to add user-defined functions and other advanced functionality through plugins, typically community-built and maintained under free-software licenses.

- Android studio: The Graphical User Interface (GUI) was designed and implemented using the Android studio because of its support for Android application development.

- Database: Firebase infrastructure was used to provide a real-time cloud-hosted database that stores user's details and login activities.

\subsection{System requirements}

These are the specifications a system must meet in order to be able to run the application smoothly. The system runs on an Android platform, stated below are the minimum requirement to run the application;

- Operating system: Android 4.4 and above

- Google Play services

- Google Play store

- 1 GB Random Access Memory (RAM)

- $1.2 \mathrm{GHz}$ processor

- Network connectivity (mobile data/Wi-Fi)

\subsection{System modelling}

Figure 2 shows the developed app's use case analysis with the various actors, association, includes, extends, and use cases associated with each of them. This model is a behaviour diagram that visually describes the functional requirements of the gamified app and the relationships between the actors and the use cases. The two main actors are the student and the farm instructor, and there are six basic Includes-Use-Cases in the UML Use Case model. 


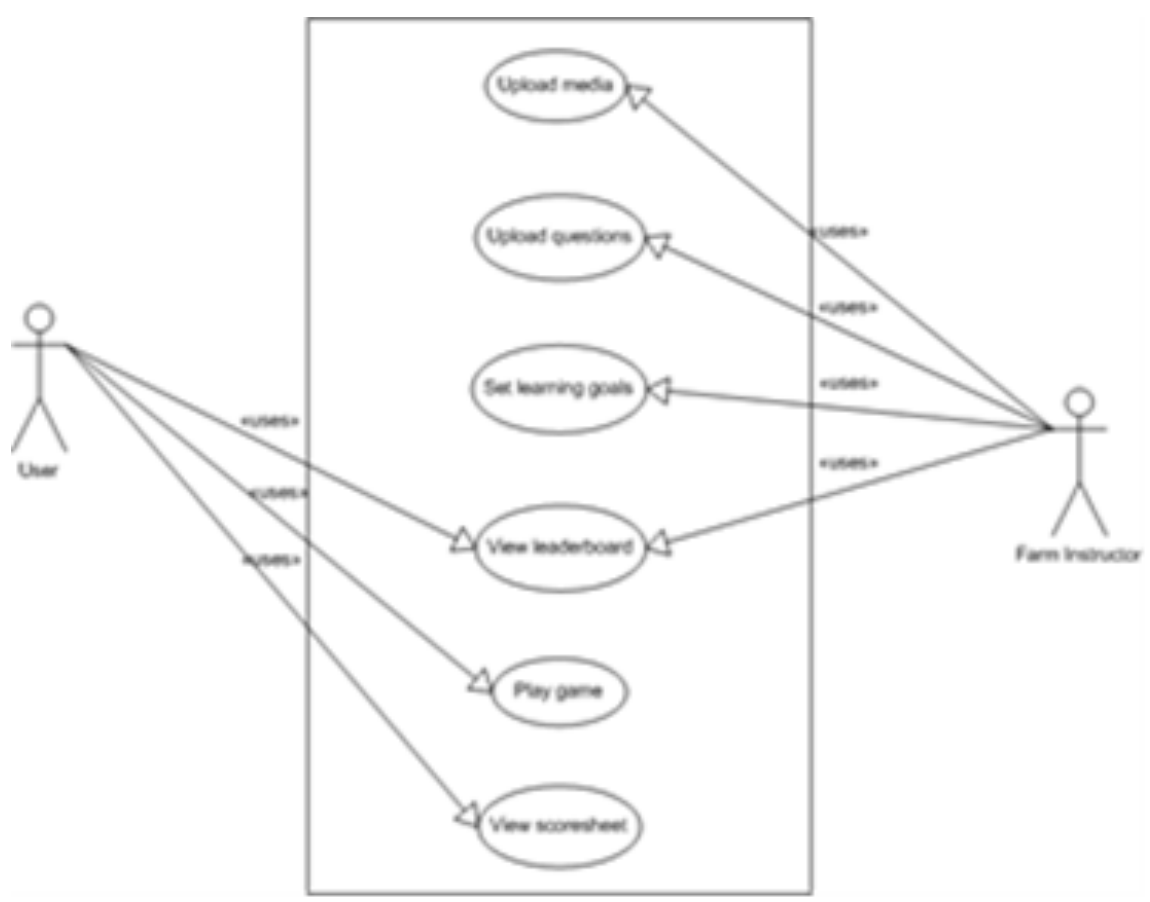

Fig. 2. App use case

\section{Results and Discussion}

The login interface is the first page of the application as seen in Figure 3. It acts as a security check phase of the application that validates users. Only registered students of Landmark University are authorized users of the application. Students are expected to login with their university webmail address details. The landing page in Figure 4 consists of all the features of the application. There are two sections of the landing page, the main landing and an addition slider menu button with more options. On the main landing page, the user's score sheet is displayed at the top in the middle for easy access and viewing. At the bottom of the screen are three icons - the leaderboard icon, start game icon, and mute icon. The top slider menu in Figure 5 displays additional options like rate this app, leaderboard, settings and logout buttons.

The game screen is the core of the application, where users accumulate point's overtime of gameplay. This interface is the interactive page between the user and the application, and users are expected to deduce an answer closest to the FP pictures displayed or based on the hints option. If a question is answered correctly the assigned point is being added to the user. Through the game interface, users can as well check their present score and view the leaderboard. The game screen has multiple views

- The game grid shown in Figure 6 
- The hint screen that is displayed when a question mark icon is clicked - shown in Figure 6

- The success screen notification in Figure 8

Which pops up after a question is answered correctly, and a "try again" notification that pops up when an answer is incorrect. Additional features included in the game helps to keep track of the total question number answered, the compilation of game score over time, and the user bonus level based on winning streak. The leaderboard in Figure 9 is the visual representation of the performance history of students based on levels attained in descending order. The game points awarded for a correct answer is 4 points, a boost of 2 points is awarded after a streak of 3 consecutive correct answers. Finally, students could rate the application based on how they feel it has affected or motivated their interest in farm practice, the interface for this rating is shown in Figure 10. The ratings range from 0 to 5 , with 0 being the lowest and 5 the highest. The chart in Figure 11 shows the rating recorded from fifty students' who used the application for a period of 30 days. Our findings show that the app is rated 5 stars, 4 stars, 3 stars, 2 stars, 1 star and 0 star by $18 \%, 52 \%, 16 \%, 12 \%, 2 \%$, and $0 \%$ of the students respectively. Likewise, the majority of the students who rated the application high (5 stars and 4 stars) have played the gamified app with the highest score of 40 and the trends shows an increased interest as the game progressed in Figure 12.

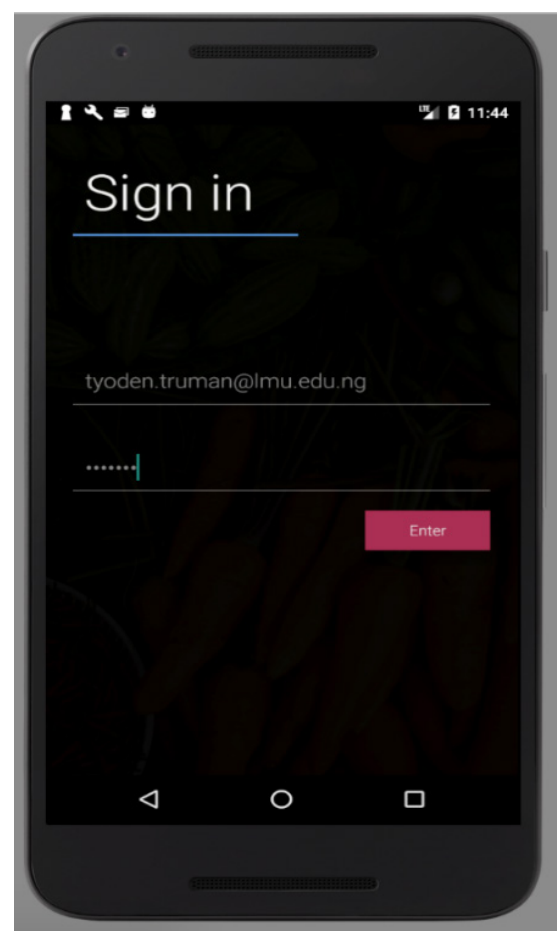

Fig. 3. Home page/ landing page 


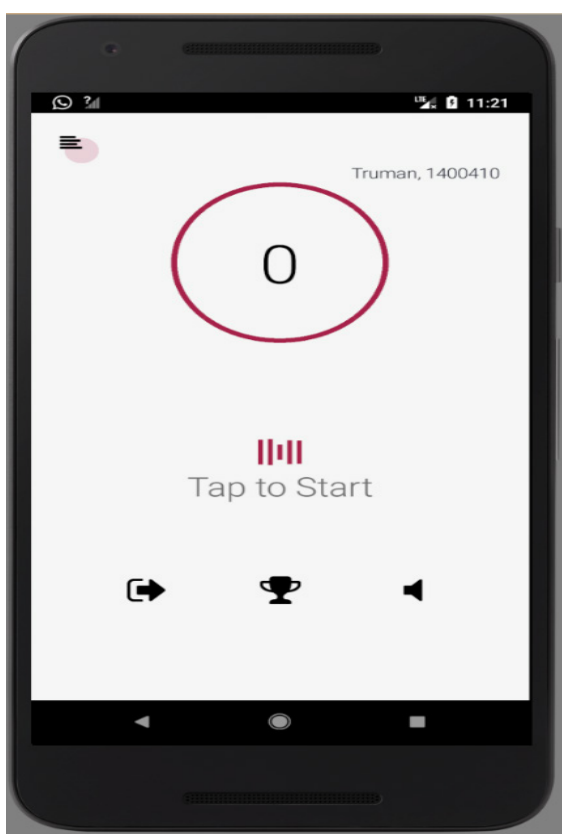

Fig. 4. Features page



Fig. 5. Slider menu 


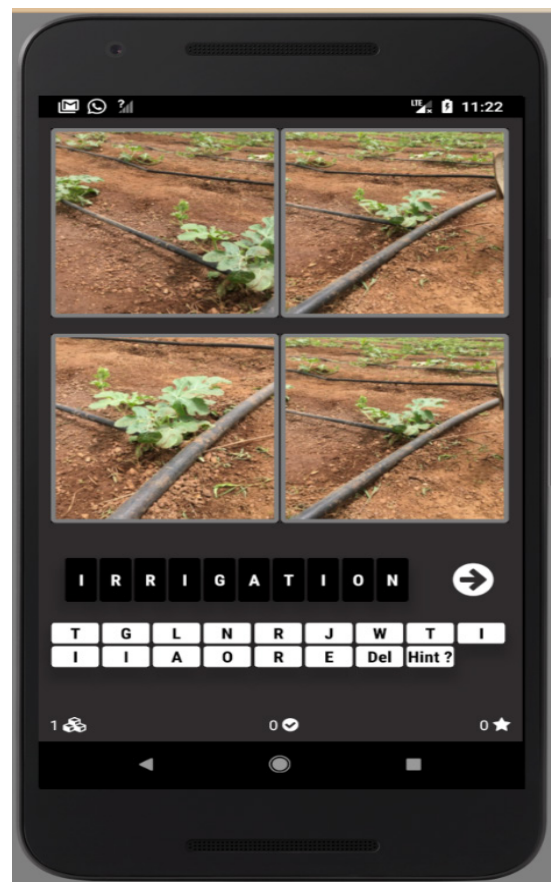

Fig. 6. Game interface

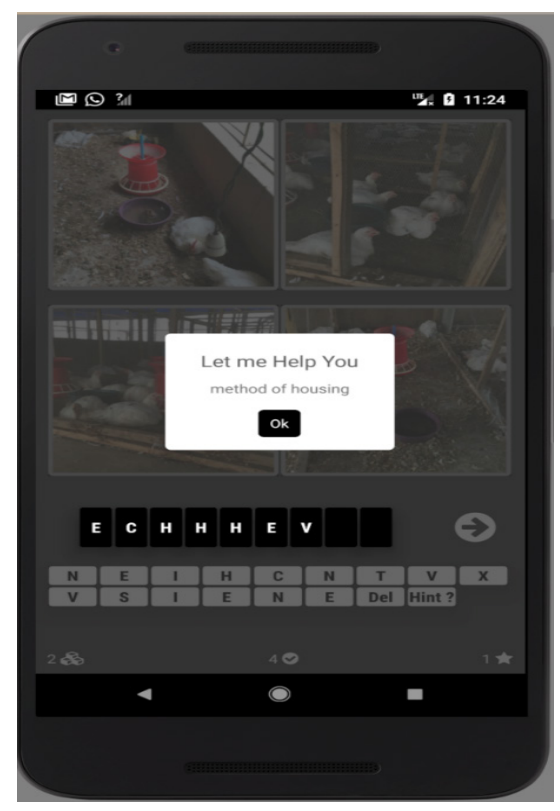

Fig. 7. The hint screen 


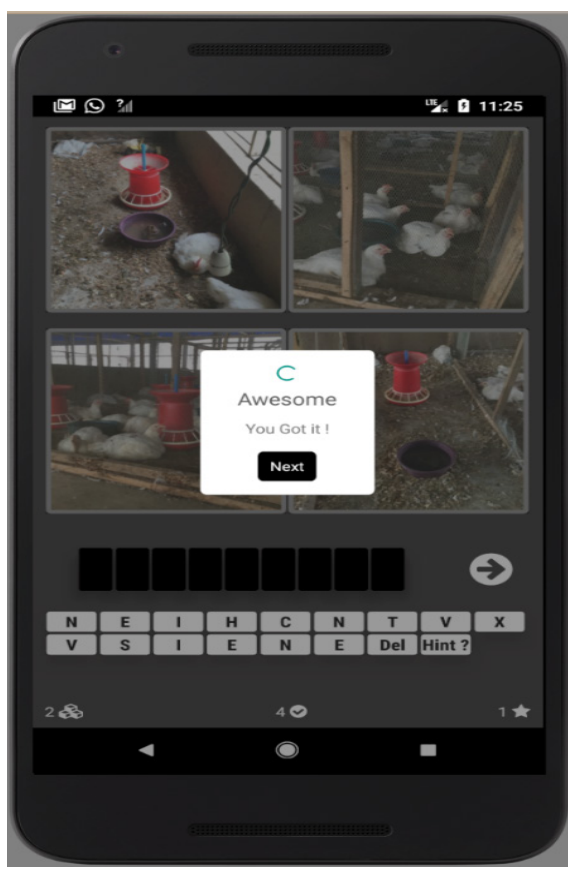

Fig. 8. The success screen notification



Fig. 9. Leaderboard 


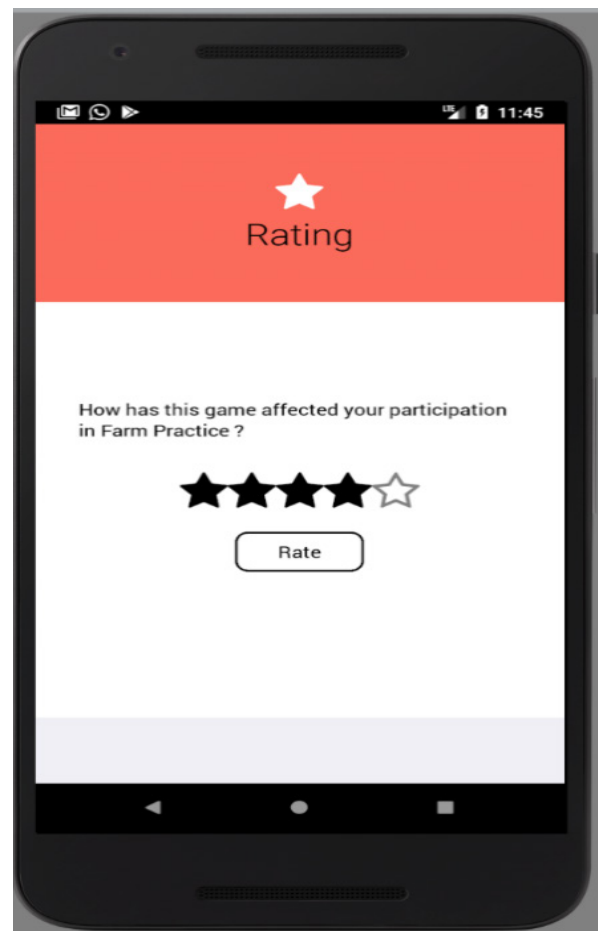

Fig. 10.Application rating

60

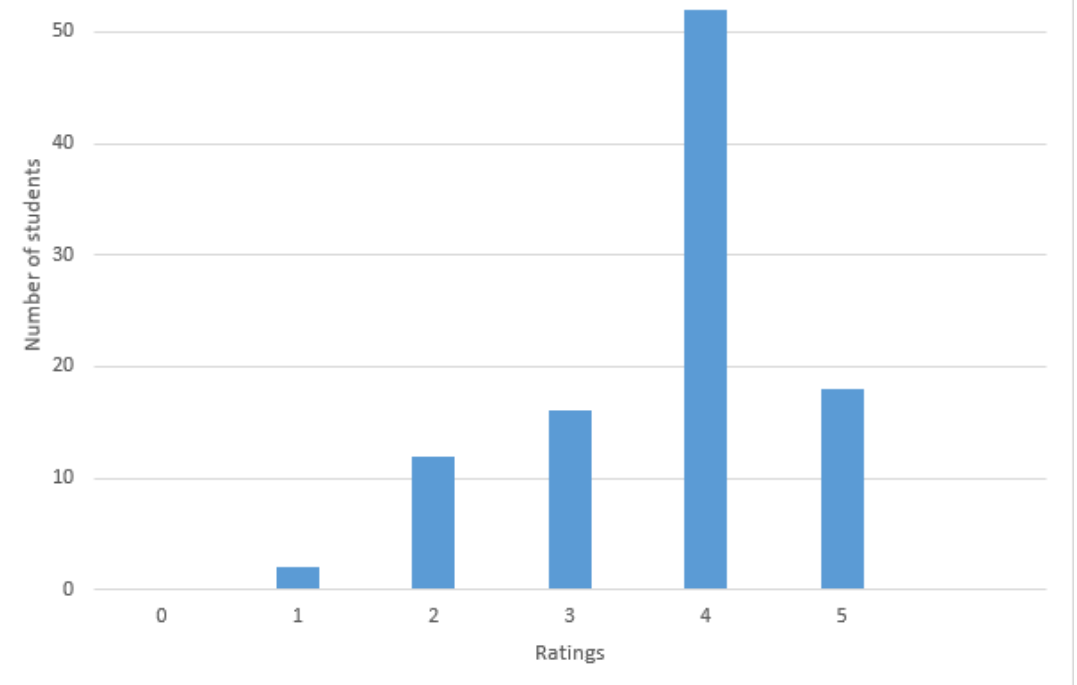

Fig. 11.Application rating by students' number 


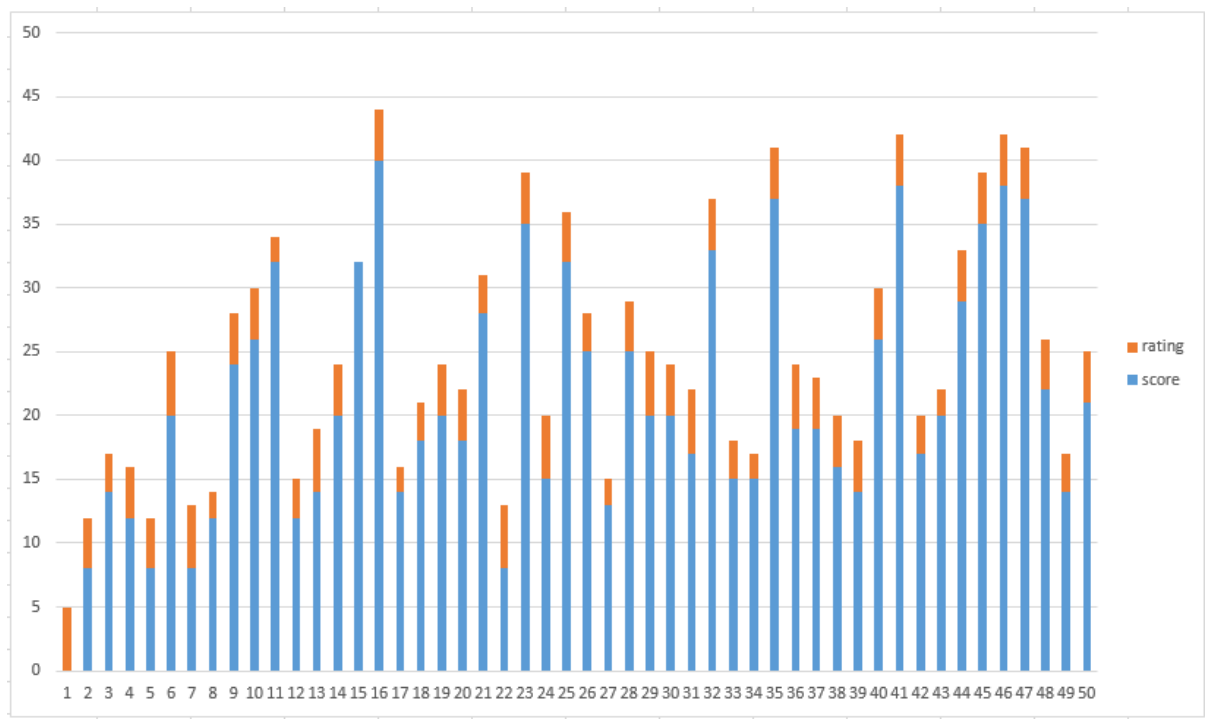

Fig. 12.Application rating by game scores

\section{Conclusion}

In this paper, gamification is simulated in a mobile application for FP in LMU. The developed prototype uses game features like points, leaderboard, and scoresheet. As a way of synergizing actual farm items and the application, only media files from LMU farms were used to develop the system. The application was evaluated by fifty users and on the average when taking the 5 stars and 4 stars rating alone, has $70 \%$ level of satisfaction. Even though there is room for improvement, the current results have shown that including fun in FP can improve learners' motivation and engagement. Gamification has been applied to the different aspect of learning and not much has been documented on gamification and agriculture. The research provided a gamified app that simulates farm practice in Landmark University. The work is limited in that it did not implement the interactive ISO 9241-210:2010 standard for human-centered design and this will be the basis for future improvement. Another limitation is the small size of the participant used in this study. Future work will include video and audio media, as well as advanced game features and a wider range of challenges.

\section{Acknowledgement}

The authors wish to thank students of Landmark University who volunteered as users of the application during testing, and the staff of Landmark University Teaching and Research Farm for their support during data gathering. 


\section{References}

[1] Muntean, C. I. (2011, October). Raising engagement in e-learning through gamification. In Proc. 6th International Conference on Virtual Learning ICVL (Vol. 1). sn.

[2] Kapp, K. M. (2012). The gamification of learning and instruction: game-based methods and strategies for training and education. John Wiley \& Sons.

[3] Armstrong, M. B., \& Landers, R. N. (2018). Gamification of employee training and development. International Journal of Training and Development, 22(2), 162-169. https://doi.org/10.1111/ijtd.12124

[4] Gouveia, P. (2015). Serious gaming: how gamers are solving real-world problems. Artech 2015, Seventh International Conference on Digital Arts, Óbidos, Portugal, 18-20 March. 147-56.

[5] Dubois, D. J., \& Tamburrelli, G. (2013, August). Understanding gamification mechanisms for software development. In Proceedings of the 2013 9th Joint Meeting on Foundations of Software Engineering (pp. 659-662). ACM. https://doi.org/10.1145/2491411.2494589

[6] Kiryakova, G., Angelova, N., \& Yordanova, L. (2014). Gamification in education. Proceedings of 9th International Balkan Education and Science Conference.

[7] Hanus, M. D., \& Fox, J. (2015). Assessing the effects of gamification in the classroom: A longitudinal study on intrinsic motivation, social comparison, satisfaction, effort, and academic performance. Computers \& Education, 80, 152-161. https://doi.org/10.101 6/j.compedu.2014.08.019

[8] Becker, K. (2007, June). Teaching teachers about serious games. In EdMedia: World Conference on Educational Media and Technology (pp. 2389-2396). Association for the Advancement of Computing in Education (AACE).

[9] Dicheva, D., Dichev, C., Agre, G., \& Angelova, G. (2015). Gamification in education: a systematic mapping study. Journal of Educational Technology \& Society, 18(3), 75.

[10] de Sousa Borges, S., Durelli, V. H., Reis, H. M., \& Isotani, S. (2014, March). A systematic mapping on gamification applied to education. In Proceedings of the 29th Annual ACM Symposium on Applied Computing (pp. 216-222). ACM. https://doi.org/10.114 $\underline{5 / 2554850.2554956}$

[11] Hitchens, M., \& Tulloch, R. (2018). A gamification design for the classroom. Interactive Technology and Smart Education, 15(1), 28-45. https://doi.org/10.1108/itse-05-2017-0028

[12] McClean, P., Saini-Eidukat, B., Schwert, D., Slator, B., \& White, A. (2001). Virtual worlds in large enrollment science classes significantly improve authentic learning. In: Proceedings of the 12th International Conference on College Teaching and Learning, Center for the Advancement of Teaching and Learning, 111-118. https://doi.org/10.1 109/icalt.2001.943848

[13] Barata, G., Gama, S., Jorge, J., \& Gonçalves, D. (2013, October). Improving participation and learning with gamification. In Proceedings of the First International Conference on gameful design, research, and applications (pp. 10-17). ACM. https://doi.org/10.114 5/2583008.2583010

[14] El Tantawi, M., Sadaf, S., \& AlHumaid, J. (2018). Using gamification to develop academic writing skills in dental undergraduate students. European Journal of Dental Education, 22(1), 15-22. https://doi.org/10.1111/eje.12238

[15] Jagušt, T., Botički, I., \& So, H. J. (2018). Examining competitive, collaborative and adaptive gamification in young learners' math learning. Computers \& Education, 125, 444-457. https://doi.org/10.1016/j.compedu.2018.06.022

[16] Haring, P., Chakinska, D., \& Ritterfeld, U. (2011). Understanding serious gaming: A psychological perspective. In Handbook of research on improving learning and motivation 
through educational games: Multidisciplinary approaches (pp. 413-430). IGI Global. https://doi.org/10.4018/978-1-60960-495-0.ch020

[17] Huang, B., \& Hew, K. F. (2015, November). Do points, badges and leaderboard increase learning and activity: A quasi-experiment on the effects of gamification. In Proceedings of the 23rd International Conference on Computers in Education (pp. 275-280).

[18] Cózar-Gutiérrez, R., \& Sáez-López, J. M. (2016). Game-based learning and gamification in initial teacher training in the social sciences: an experiment with MinecraftEdu. International Journal of Educational Technology in Higher Education, 13(1), 2. https://doi.org/10.1186/s41239-016-0003-4

[19] O'Donnell, N., Kappen, D. L., Fitz-Walter, Z., Deterding, S., Nacke, L. E., \& Johnson, D. (2017, October). How Multidisciplinary is Gamification Research?: Results from a Scoping Review. In Extended Abstracts Publication of the Annual Symposium on ComputerHuman Interaction in Play (pp. 445-452). ACM. https://doi.org/10.1145/3130859.3131412

[20] Parlić, D., Čudanov, M., \& Săvoiu, G. (2014). Multidisciplinary Apporach To Increasing Creativity: Gamification In Organizational Context. Econophysics, Sociophysics \& Other Multidisciplinary Sciences Journal (ESMSJ) Staff, 21(4), 1.

[21] O'Donovan, S., Gain, J., \& Marais, P. (2013, October). A case study in the gamification of a university-level games development course. In Proceedings of the South African Institute for Computer Scientists and Information Technologists Conference (pp. 242-251). ACM. https://doi.org/10.1145/2513456.2513469

[22] Bergeron, B. (2006). Developing serious games (game development series).

[23] Ritterfeld, U., Cody, M., \& Vorderer, P. (Eds.). (2009). Serious games: Mechanisms and effects. Routledge.

[24] Deif, A. (2017). Insights on lean gamification for higher education. International Journal of Lean Six Sigma, 8(3), 359-376.

[25] Feldotto, M., John, T., Kundisch, D., Hemsen, P., Klingsieck, K., \& Skopalik, A. (2017, May). Making Gamification Easy for the Professor: Decoupling Game and Content with the StudyNow Mobile App. In International Conference on Design Science Research in Information System and Technology (pp. 462-467). Springer, Cham. https://doi.org/10.1 007/978-3-319-59144-5 32

[26] Lieberoth, A. (2015). Shallow gamification: Testing psychological effects of framing an activity as a game. Games and Culture, 10(3), 229-248. https://doi.org/10.11 $\underline{77 / 1555412014559978}$

[27] Chernbumroong, S., Sureephong, P., \& Muangmoon, O. O. (2017, March). The effect of leaderboard in different goal-setting levels. In 2017 International Conference on Digital Arts, Media and Technology (ICDAMT) (pp. 230-234). IEEE. https://doi.org/10.1 $\underline{109 / i c d a m t .2017 .7904967}$

\section{Authors}

Adebayo Omotosho received his $\mathrm{PhD}$ in Computer Science at Ladoke Akintola University of Technology in 2016. He is a Seasoned Computer Programmer and has taken part in several programming competitions in $\mathrm{C} / \mathrm{C}++/ \mathrm{CH}$. He is a member of the Nigeria Computer Society (NCS), Computer Professional [Registration Council] of Nigeria (CPN), Computer Science Teachers Association for Computing Machinery (ACM), and International Association of Computer Science and Information Tech- 
nology. His research interests are health informatics, computer security, machine learning, and biometrics.

Truman Tyoden holds a BSc in Computer Science from Landmark University Omu-Aran. His research interests are gamification and system development.

Peace Ayegba is a research assistant in the Department of Computer Science, Landmark University Omu-Aran. She is currently on her MSc degree and her research areas are computer security, human-computer interaction, artificial intelligence and bioinformatics.

Joyce Ayoola is a graduate assistant in the Department of Computer Science, Landmark University Omu-Aran. She is currently on her MSc degree and her research areas are computational complexity and software development.

Article submitted 2018-08-20. Resubmitted 2019-02-24. Final acceptance 2019-03-01. Final version published as submitted by the authors. 